\title{
Effect of maternal excessive iodine intake on neurodevelopment and cognitive function in rat offspring
}

Le Zhang ${ }^{1,2}$, Weiping Teng ${ }^{1,2^{*}}$, Yuhui Liư ${ }^{2}$ Jing Li ${ }^{1,2}$, Jinyuan Mao ${ }^{2}$, Chenling Fan², Hong Wang ${ }^{2}$, Hongmei Zhang ${ }^{2}$ and Zhongyan Shan ${ }^{1,2^{*}}$

\begin{abstract}
Background: lodine deficiency and iodine excess are both associated with adverse health consequences. lodine deficiency during pregnancy leads to insufficient maternal thyroid hormone, subsequently causing irreversible adverse effects on the neurological and cognitive functions of the offspring. The results of our previous epidemiological study suggested that mild iodine excess might increase the prevalence of subclinical hypothyroidism. In the present study, female Wistar rats maintained on low-iodine grain were randomly assigned to three groups based on iodated water concentration: low iodine (LI, $1.2 \mu \mathrm{g} / \mathrm{d})$, normal iodine ( $\mathrm{NI}, 5-6 \mu \mathrm{g} / \mathrm{d})$, and 3-fold high iodine $(3 \mathrm{HI}, 15-16 \mu \mathrm{g} / \mathrm{d})$. The present study investigated whether higher-than-normal iodine intake $(3 \mathrm{HI})$ by rats from before pregnancy until breastfeeding affects the postnatal (PN) neurodevelopment (PN7 and PN45) of their offspring during particularly sensitive periods in brain development.
\end{abstract}

Results: After 12 weeks of treatment (before pregnancy), iodine concentrations in urine and thyroid tissue and circulating thyroxine of adult females correlated with iodine intake. Brain-derived neurotrophic factor (BDNF) expression in the hippocampi of pups on PN7 and PN45 was decreased in 3HI group compared to the NI controls ( $P<0.05$, all) On PN7 and PN45, the BDNF levels of the $3 \mathrm{HI}$ pups were $83.5 \%$ and $88.8 \%$, respectively, that of the NI pups. In addition, the $3 \mathrm{HI}$ group had a higher neuroendocrine-specific protein A (NSP-A) level than the NI controls on PN7 $(P<0.05)$. NSP-A levels of the $3 \mathrm{HI}$ pups were $117.0 \%$ that of the NI pups. No significant difference was observed in the expressions of c-Fos or c-Jun in the hippocampal CA1 region of the $3 \mathrm{HI}$ group compared to the controls $(P>0.05)$. Results from the Morris water maze test revealed that pups of the $3 \mathrm{HI}$ group had mild learning and spatial memory deficits.

Conclusions: The neurodevelopmental and cognitive deficits of the $3 \mathrm{HI}$ pups were mild and temporary, likely related to the changes in hippocampal protein expressions of BDNF and NSP-A.

Keywords: lodine deficiency, lodine excess, Thyroid hormone, Hippocampus, Neurodevelopment

\section{Background}

Iodine is essential for the synthesis of thyroid hormone, including during pregnancy. Maternal thyroid hormones have essential roles in foetal brain development, regulating both morphological and biochemical changes before the onset of foetal thyroid function [1,2]. Moderate and

\footnotetext{
* Correspondence: shanzhongyan@medmail.com.cn

'Department of Endocrinology and Metabolism, First Affiliated Hospital of China Medical University, Shenyang 110001, People's Republic of China ${ }^{2}$ Endocrinology Institute of China Medical University, Liaoning Provincial Key Laboratory of Endocrine Diseases, Shenyang 110001, People's Republic of China
}

severe iodine deficiency during pregnancy leads to insufficient maternal thyroid hormone, subsequently causing irreversible adverse effects on the neurological and cognitive functions of the offspring [3-5]. In China the Universal Salt Iodization (USI) policy was implemented in 1996 and since then the average resident's iodine status was in excess for three years and more than adequate for six years. Previously, we conducted a five-year follow-up study from 1999 to 2004 to evaluate the effect of different iodine intake on thyroid diseases. We found that more than adequate (median urinary iodine [MUI] $243 \mu \mathrm{g} / \mathrm{L}$ ) and iodine excess (MUI $651 \mu \mathrm{g} / \mathrm{L}$ ) could

\section{Biomed Central}


increase the prevalence of subclinical hypothyroidism [6]. However whether more than adequate and excessive iodine intake can affect the neurodevelopment of the offspring has not been investigated.

The genes c-Fos and c-Jun are essential for spatial learning and memory consolidation in rats, and hypothyroidism due to iodine deficiency is associated with reduced expressions of c-Fos and c-Jun in the rat hippocampal CA1 region [7-9]. Maternal hypothyroidism affects the expression of foetal and neonatal brainderived neurotrophic factor (BDNF) [10,11] and neuroendocrine-specific protein (NSP)-A [12], both of which are important mediators of thyroid hormone and have essential roles in brain development.

In our present study, female Wistar rats were maintained on low-iodine grain and randomly assigned to three groups based on the iodated water concentration: low iodine (LI), normal iodine (NI), and 3-fold high iodine $(3 \mathrm{HI})$ groups. Furthermore we explored whether maternal iodine excess in rats could lead to changes in neurological function in offspring.

\section{Results}

\section{Urinary and thyroidal iodine content}

Urine iodine concentrations of the adult female rats paralleled their iodine intake; urine and tissue iodine concentrations increased gradually with increasing iodine intake. In the low iodine (LI) group, urinary iodine was only $20.27 \%$ that of the normal iodine (NI) group, and the thyroidal iodine was $15.37 \%$ that of the NI group. At the same time, the 3 -fold iodine (3HI) group had significantly elevated concentrations of iodine in urine and thyroid tissue, which was $307.16 \%$ and $141.92 \%$, respectively, that of the NI group $(P<0.05$, all; Table 1$)$.

\section{Maternal and pup thyroid hormone}

Maternal thyroid hormone: After 12 weeks of treatment (pre-pregnancy), total thyroxine $\left(\mathrm{TT}_{4}\right)$ and free thyroxine $\left(\mathrm{FT}_{4}\right)$ concentrations in the sera of the adult females were significantly lower in the LI group compared with those in the NI $\left(P<0.05\right.$, all). $\mathrm{TT}_{4}$ and $\mathrm{FT}_{4}$ levels in the maternal serum were significantly higher in the $3 \mathrm{HI}$ group than those in NI control group $(P<0.05$, all). On

Table 1 lodine concentration in thyroid tissue and urine of pre-pregnant females after 12 weeks of treatment

\begin{tabular}{lcc}
\hline & \multicolumn{2}{c}{ Iodine concentration $(\boldsymbol{\mu g} / \mathrm{L})$} \\
\cline { 2 - 3 } & Urine & Thyroid tissue \\
\hline $\mathrm{LI}$ & $37.48 \pm 25.89 *$ & $77.78 \pm 33.19 *$ \\
$\mathrm{NI}$ & $184.90 \pm 23.27$ & $506.05 \pm 39.62$ \\
$3 \mathrm{HI}$ & $567.93 \pm 69.84 *$ & $718.20 \pm 33.19 *$ \\
\hline
\end{tabular}

Values are expressed as the mean \pm SEM ( $n=6$ for each group). ${ }^{*} P<0.05$ compared with normal iodine control group. gestational $(\mathrm{G})$ day $17, \mathrm{TT}_{4}$ and $\mathrm{FT}_{4}$ concentrations in sera of the adult females remained significantly lower in the LI group compared with those in the NI $(P<0.05$, all), while the $3 \mathrm{HI}$ group still exhibited significantly higher circulating $\mathrm{TT}_{4}$ level compared with the control group $(P<0.05)$. However, on $\mathrm{G} 17$ the level of $\mathrm{FT}_{4}$ was a increasing trend, however no significant difference in $\mathrm{FT}_{4}$ concentration between the NI and 3HI groups. After 12 weeks of treatment (pre-pregnancy) and on G17, thyroid stimulating hormone (TSH) concentrations were significantly higher in the LI group compared with the NI $(P<0.05$, all), while there were descending trends, although no significant changes were found in the TSH levels after 12 weeks of treatment (pre-pregnancy) and on $\mathrm{G} 17$ in the $3 \mathrm{HI}$ rats compared with these levels in the NI $(P>0.05$; Table 2).

Pup thyroid hormone: On postnatal (PN) day 7 (PN7) and day 45 (PN45), the sera of pups in the LI group had significantly higher TSH levels, and lower $\mathrm{TT}_{4}$ and $\mathrm{FT}_{4}$ levels, than those in the NI group $(P<0.05$, all $)$. On PN7, pups from the $3 \mathrm{HI}$ group had a significantly higher serum TSH level compared with NI pups $(P<0.05)$. However, there was no significant difference between the $3 \mathrm{HI}$ and NI groups in $\mathrm{TT}_{4}$ and $\mathrm{FT}_{4}$ levels. On PN45 there was no significant difference in any of the serum thyroid hormone levels between pups of the 3HI and NI groups $(P>0.05$, all; Table 3$)$. This indicated that the thyroid dysfunction of the pups from the $3 \mathrm{HI}$ group could be rectified by PN45.

\section{Effect of $3 \mathrm{HI}$ on the protein expressions of c-Fos and c- Jun in the CA1 area of hippocampus}

Photomicrographs of the immunohistochemistry-stained hippocampal tissues from PN7 pups showed positive expression of c-Fos and c-Jun in area CA1 in all treatment groups (Figure 1A-F). The IOD values of $\mathrm{c}$-Fos and c-Jun in CA1 area were significantly decreased in the pups of the LI group compared with control pups $(P<0.05)$. However, there was no significant difference in c-Fos and c-Jun expressions between the 3HI and NI groups $(P>0.05)$. On PN45, the expression of $\mathrm{c}$-Fos and c-Jun in the LI group was also the lowest among the three groups $(P<0.05)$. There was no significant difference in the expressions of c-Fos and c-Jun in CA1 region of hippocampus between the $3 \mathrm{HI}$ pups and dams of the NI group $(P>0.05)$.

\section{Effect of $3 \mathrm{HI}$ on BDNF and NSP-A expression in the hippocampus}

On PN7 and PN45, BDNF protein expression levels were significantly lower in both the LI and 3HI pups compared with the NI controls. Specifically, on PN7 the BDNF levels in the pups of the LI group were $58.84 \%$ that of the NI $(P<0.01)$, and the BDNF levels of the 
Table 2 Maternal thyroid hormone levels of the three treatment groups during pre-pregnancy and G17

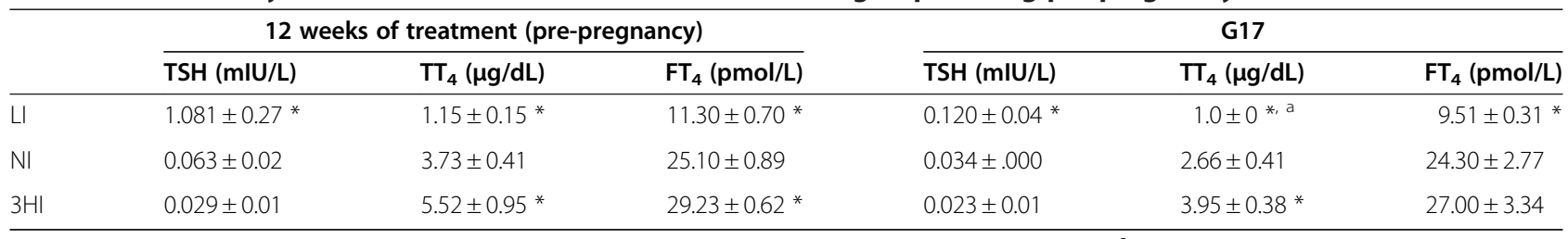

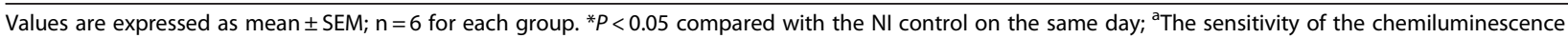
immunoassay for $\Pi_{4}$ was $1.0 \mu \mathrm{g} / \mathrm{dL}$.

pups in the $3 \mathrm{HI}$ group were $83.5 \%$ that of the NI $(P<0.05)$. On PN45, the BDNF levels in the pups of the LI group were $59.78 \%$ that of the NI $(P<0.01)$, and the BDNF levels of the pups in the $3 \mathrm{HI}$ group were $88.8 \%$ that of the NI $(P<0.05$; Figure $2 \mathrm{~A}$ and $\mathrm{C})$.

On the other hand, on PN7 the expression of NSP-A was higher in the LI and $3 \mathrm{HI}$ pups when compared with the NI controls: The levels of NSP-A of the LI and 3HI pups were $136.7 \%$ and $117.0 \%$, respectively, that of the NI pups $(P<0.01$ and $P<0.05$, respectively). NSP-A protein expression levels were significantly higher in the LI pups compared with the NI controls on PN45. The levels of NSP-A of the LI pups were $123.6 \%$ that of the NI pups $(P<0.05)$. However, no significant differences in the NSP-A levels were observed between the $3 \mathrm{HI}$ dams and NI dams on PN45 ( $P>0.05$; Figure 2B and D).

\section{Morris water maze (MWM) test}

To evaluate whether various levels of iodine intake during gestation could cause cognitive and behavioral alterations in offspring, the pups underwent the MWM test on PN40-44. The time to reach the hidden platform (escape latency times) of all treatment groups became shorter as the number of training trials increased. However, the escape latencies were significantly longer for pups in the LI group compared with the NI group. Interestingly, our data showed that the $3 \mathrm{HI}$ pups took more time than the controls to learn the spatial cues required to find the hidden platform for all 5 days of testing, and there was a statistical difference when compared with the NI control group on the third day $(P<0.05$; Figure 3$)$.

\section{Discussion}

Much recent attention has focused on elucidating the effects of iodine deficiency on neurodevelopmental impairment $[13,14]$. However, the effects of iodine excess should not be overlooked. We investigated whether and how a 3-fold increase in the physiological dose of iodine in rat would affect brain development of their offspring. The rat brain at PN7 is considered developmentally equivalent to the human brain at birth [15]. Rat brain development at PN21 approximates the late toddler stage of humans, and PN45 equates to the teenager stage [16]. We selected PN7 and PN45 as two crucial time points in the brain development of the rat to explore the effect of maternal excessive iodine intake on the neurodevelopment and cognitive function in their offspring. Our results show for the first time that there were changes in BDNF and NSP-A expression and neurodevelopmental impairment in rat pups whose mothers had a 3-fold higher-than-normal intake of iodine prior to pregnancy and throughout gestation and breastfeeding.

Iodine intake levels that are either lower or higher than the recommended range are associated with an increase in the incidence of thyroid disease in China [6]. Both thyroid hormone deficiency and excess have detrimental effects on the expression of neuronal proteins during neurodevelopmental stages $[17,18]$.

Iodine deficiency is the most common cause of hypothyroidism. The results of some studies regarding excess iodine suggested that high iodine intake was associated with increased incidence of hypothyroidism $[19,20]$, while others found that it led to hyperthyroidism [21,22]. These different results may be related to the duration of high iodine exposure. The incidence of hyperthyroidism after the initiation of the Universal Salt Iodization (USI) program began to rise at about 6 months, peaked at 1-3 years and returned to the baseline within 3-10 years [23-25]. Iodine-induced thyrotoxicosis lasting the first few years after the implementation of iodine supplementation was reported in Lesotho [26] and Poland [27]. However our epidemiological study demonstrated that there was no

Table 3 Hormone levels in offspring of the three treatment groups on PN7 and PN45

\begin{tabular}{|c|c|c|c|c|c|c|}
\hline & \multicolumn{3}{|c|}{ PN7 } & \multicolumn{3}{|c|}{ PN45 } \\
\hline & TSH (mIU/L) & $\mathrm{TT}_{4}(\mu \mathrm{g} / \mathrm{dL})$ & $\mathrm{FT}_{4}(\mathrm{pmol} / \mathrm{L})$ & TSH (mlU/L) & $\mathrm{TT}_{4}(\mu \mathrm{g} / \mathrm{dL})$ & $\mathrm{FT}_{4}(\mathrm{pmol} / \mathrm{L})$ \\
\hline $\mathrm{LI}$ & $0.157 \pm 0.03 *$ & $1.48 \pm 0.99 *$ & $7.71 \pm 0.24$ * & $0.320 \pm 0.06 *$ & $2.84 \pm 0.32 *$ & $23.62 \pm 1.25^{*}$ \\
\hline $\mathrm{NI}$ & $0.079 \pm 0.01$ & $2.44 \pm 0.10$ & $10.35 \pm 0.34$ & $0.061 \pm 0.01$ & $4.86 \pm 0.61$ & $34.68 \pm 3.01$ \\
\hline $3 \mathrm{HI}$ & $0.142 \pm 0.02 *$ & $2.45 \pm 0.18$ & $9.69 \pm 0.32$ & $0.080 \pm 0.02$ & $5.03 \pm 0.53$ & $33.80 \pm 1.87$ \\
\hline
\end{tabular}

Values are expressed as mean $\pm \mathrm{SEM} ; \mathrm{n}=6$ for each group. ${ }^{*} P<0.05$ compared with $\mathrm{NI}$ control on the same day. 

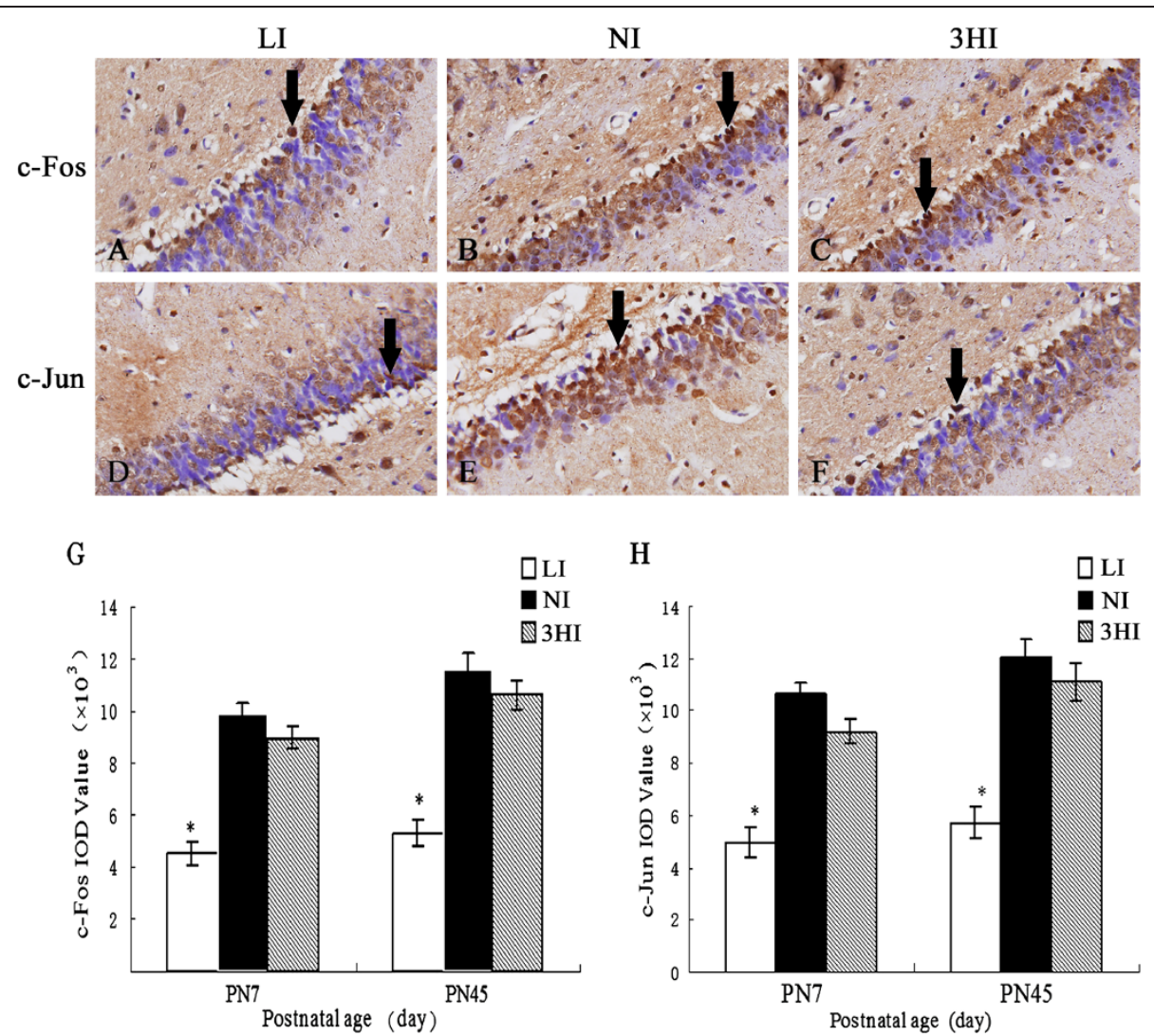

Figure 1 Expression of c-Fos and c-Jun in the hippocampal CA1 area of pups on PN7 and PN45. Upper three photomicrographs (A-C) show the expression of C-Fos in the CA1 of the $\mathrm{LI}(\mathrm{A}), \mathrm{NI}(\mathrm{B})$, and 3HI (C) groups. Lower three photomicrographs (D-F) show the expression of c-Jun in the CA1 of the $\mathrm{LI}(\mathrm{D}), \mathrm{NI}(\mathrm{E})$, and $3 \mathrm{HI}(\mathrm{F})$ groups. $\mathbf{G}$ and $\mathbf{H}$ represent the IOD values of c-Fos and c-Jun expressions in CA1 on PN7 and PN45, respectively. Data are expressed as the mean \pm SEM ( $n=6$, for each group). ${ }^{*} P<0.05$ compared with the NI control group on the same day.

difference in either the prevalence or the incidence of hyperthyroidism among mildly deficient, more than adequate, and excessive iodine intake areas (MUI 84, 243, and $651 \mu \mathrm{g} / \mathrm{L}$, respectively). We found that more than adequate and excessive iodine intake could increase the prevalence of subclinical hypothyroidism [6]. The USI policy had been implemented for 3 to 8 years in China, since 1996, when we conducted the epidemiological study from 1999 to 2004. Therefore we did not obtain epidemiological data for the early stage of iodine supplementation.

In the present animal study, after 12 weeks of treatment (pre-pregnancy), the serum $\mathrm{TT}_{4}$ and $\mathrm{FT}_{4}$ levels were significantly higher in the adult female rats of the $3 \mathrm{HI}$ group compared with those of the NI group. On G17, the $\mathrm{TT}_{4}$ concentration of the adult females remained the higher level in the $3 \mathrm{HI}$ group compared with that of the NI. Although no significant changes were found in the TSH levels on pre-pregnancy and G17 in the 3HI rats compared with those of the NI, there were descending trends in the $3 \mathrm{HI}$ group.
Before the onset of foetal thyroid function in both humans (10-12 weeks gestation) and rats (G17), early foetal brain development is completely dependent on maternal thyroxine $\left(\mathrm{T}_{4}\right)$ supply [28]. Even after the foetal thyroid has begun to secrete hormone, as much as $17.5 \%$ of foetal $\mathrm{T}_{4}$ derives from transplacental transfer [29]. Recent studies have reported that excess thyroid hormone could impair foetal brain development and affect the neurological outcome of rat offspring [30,31]. Excessive iodine intake has been shown to inhibit foetal thyroid function and lead to iodine-induced neonatal hypothyroidism in Asian populations [32]. Our previous study [33] found that excessive iodine intake increased the risk of subclinical hypothyroidism in offspring. Furthermore, excessive iodine content from breast milk caused subclinical hypothyroidism in preterm infants [34]. These studies were consistent with our finding in the present study that maternal iodine excess caused subclinical hypothyroidism of rat pups on PN7, although the thyroid hormone levels of pups in the $3 \mathrm{HI}$ group 

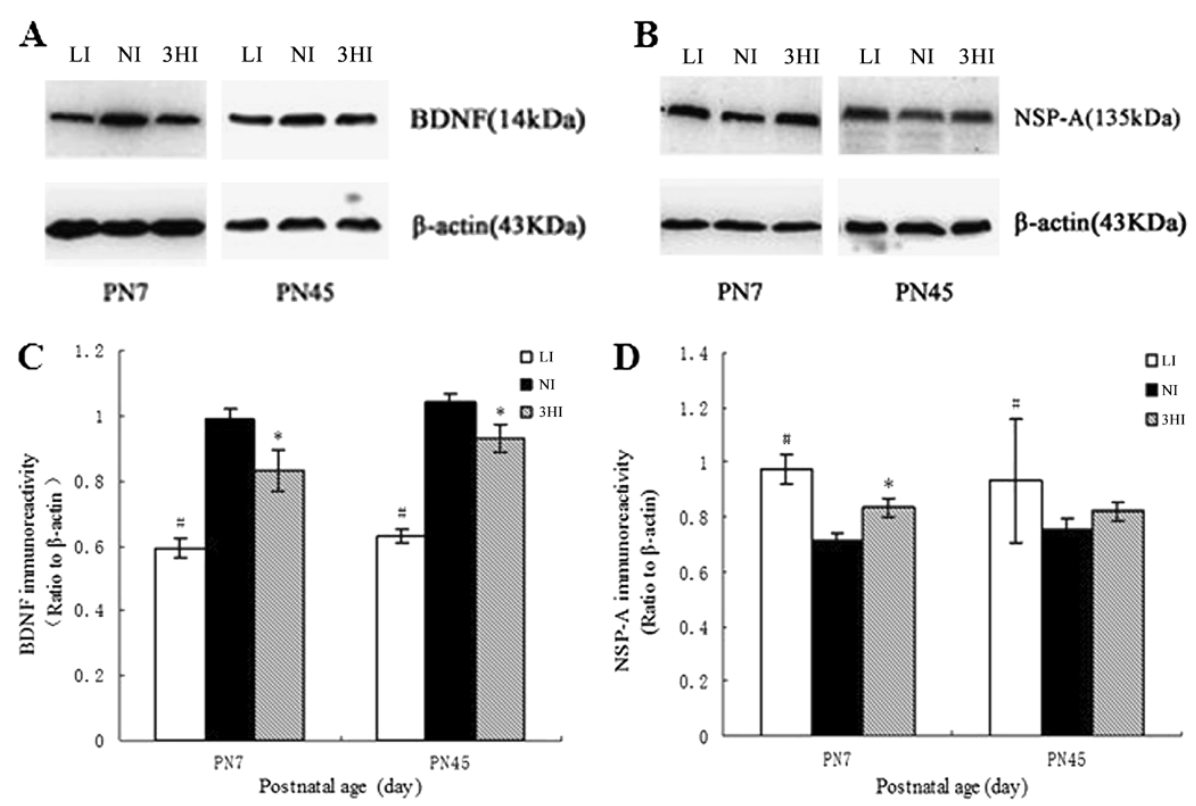

Figure 2 Protein expression levels of BDNF and NSP-A in the pup hippocampus on PN7 and PN45. A and B: protein levels determined via Western blot. $\mathbf{C}$ and $\mathbf{D}$ : Ratios of NSP-A/ $\beta$-actin and BDNF/ $\beta$-actin immunoreactive densities were determined for each group. The expression of the two proteins was normalized to $\beta$-actin. The height of each bar represents the mean \pm SEM ( $n=6$ for each group). ${ }^{*} P<0.05$ compared with the $\mathrm{Nl}$ group on the same day; ${ }^{\#} P<0.01$ compared with the NI group on the same day.

were within the normal range on PN45. Our results indicated that maternal thyroid hormone disruption during sensitive periods of brain development caused by mildly maternal iodine excess could lead to thyroid dysfunction of pups and cause neurodevelopmental defects in offspring.

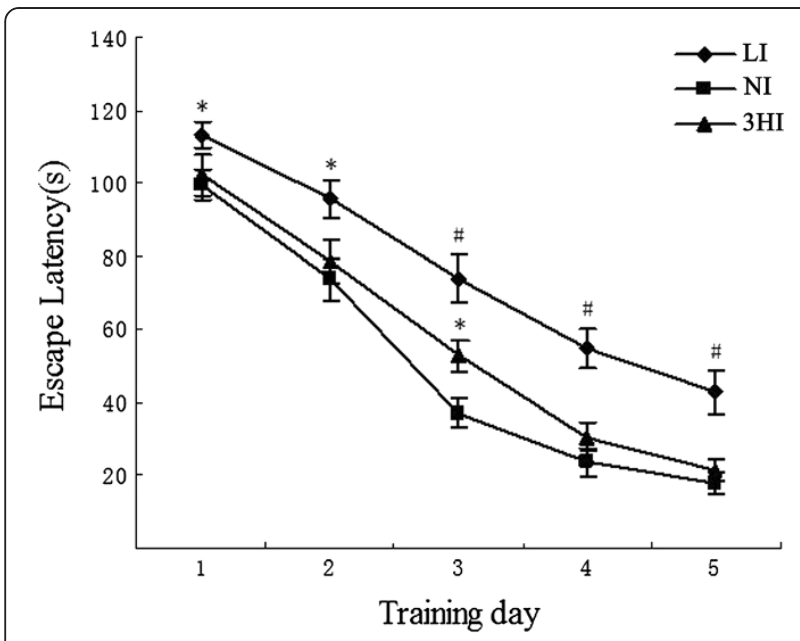

Figure 3 Performance of pups in the Morris water maze. Data are expressed as the mean \pm SEM ( $n=10$ for each group). ${ }^{*} P<0.05$

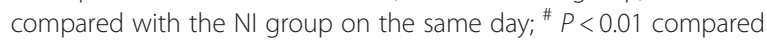
with the NI group on the same day.
The proteins c-Fos and c-Jun in the nuclei of neurons are involved in neuroplastic mechanisms and neuronal differentiation, and also have important roles in memory formation and consolidation [8,35]. In our study, c-Fos and c-Jun expression in the hippocampal CA1 area of rat pups was not significantly affected by the 3 -fold high iodine intake of their mothers during gestation. It is possible that compensatory mechanisms restored c-Fos and c-Jun to normal levels in spite of maternal thyroid dysfunction. Another possibility is that c-Fos and c-Jun were not involved in the neurodevelopmental impairment of pups from the $3 \mathrm{HI}$ group.

BDNF, a neurotrophin protein, has significant influence on crucial processes of brain development, including neurogenesis, neuronal differentiation, synaptogenesis, memory formation, and consolidation [36-39]. Previous reports have documented that maternal thyroid dysfunction could affect the expression of BDNF and cause neurological defects in neonates [40] and adult rats [11]. Our previous studies $[10,41]$ reported that maternal subclinical hypothyroidism decreased BDNF expression in rat pup hippocampi and impaired spatial learning; pups required more time during the Morris water maze test to find the hidden platform, compared with pups from NI mothers. The present study found that BDNF protein levels were decreased in the hippocampi of the pups from both the 3HI and LI mothers. On PN45, the BDNF expression in the $3 \mathrm{HI}$ pups remained lower than control 
pups, although circulating levels of thyroid hormone had fully recovered. Our study indicated that a persistently lower BDNF level may contribute to the adverse effect of $3 \mathrm{HI}$ on the developing brain. However, the impairment was mild compared with hypothyroidism induced by iodine deficiency.

NSP-A is known to be an important mediator of thyroid hormone effects during brain development and is involved in neuronal differentiation and axonal guidance [42]. Dowling et al. [12,43] showed that the expression of NSP-A was regulated by thyroid hormone, and the expression of NSP-A was selectively affected by maternal hypothyroidism in the proliferative zone of the fetal rat brain cortex. Our data also found that the expression of NSP-A in the hippocampus on PN7 was affected by mildly maternal excessive iodine intake. The abnormal expression of NSP-A in the neonatal brain appears to be related to the neurodevelopmental impairment in the pups of the $3 \mathrm{HI}$ group, but the impairment was less severe than pups in the LI group.

In this study, spatial learning ability and memory of the rat pups were assessed using the MWM test on PN40-44. Pups in the LI group required more time to find the hidden platform, compared with pups from NI mothers. The severe impairment of spatial and learning ability was associated with the thyroid dysfunction and abnormal levels of proteins related to neurodevelopment, which were not reversed by PN45 in LI group, and the neurodevelopmental impairment thus appeared to be permanent. The mean escape latency of $3 \mathrm{HI}$ pups was longer than for the NI control pups, and the difference was significant on the third day (PN42; $P<0.05)$. Our results suggested that the offspring in the $3 \mathrm{HI}$ group may have had a mildly impaired learning capacity, which could be associated with a decrease in BDNF and an increase in NSP-A levels. The mild spatial learning and memory impairment was temporary, which was consistent with the recovery of NSP-A expression on PN45, and the long-term effects of mildly maternal excessive iodine intake on neurodevelopment and cognitive function need to be investigated in our future study.

\section{Conclusions}

In summary, this study found that both low and high levels of iodine intake by rats could affect the neurological development of offspring. Reduced the expression of BDNF and enhanced that of NSP-A during hippocampal development of the offspring might be related with the impaired cognitive functions. However the impairment induced by maternal 3-fold high iodine intake was mild and temporary, which suggested that careful control of maternal iodine intake level is important to prevent neurodevelopmental defects in offspring.

\section{Methods}

\section{Animals}

Specific Pathogen-Free (SPF) female Wistar rats $(n=60)$ weighing 80-120 g were obtained from HFK Bioscience Laboratory Animal (Beijing, China). The Animal Research Committee of China Medical University approved this study. All experiments and procedures were carried out in accordance with the Guide for the Care and Use of Laboratory Animals mandated by the National Institutes of Health. Rats were housed under SPF conditions at $24 \pm 2{ }^{\circ} \mathrm{C}$ under automatic 12 - h light and 12 - $\mathrm{h}$ dark cycles.

Animals were randomly assigned to one of three treatment groups $(\mathrm{n}=20$, each): LI, NI, and 3HI. All groups were administered a low iodine diet $(60 \mu \mathrm{g}$ iodine per $\mathrm{kg}$ of feed, or $1.2 \mu \mathrm{g}$ iodine in $20 \mathrm{~g}$ of feed per rat per day) of corn $(73 \%)$, millet (20\%), and soybean (7\%) obtained from an area that is severely iodine-deficient (Hebei, China). Other chemical and trace elements were added, based on the standard American Institute of Nutrition (AIN)-93 diet. With the exception of iodine content, the rats' food was nutritionally complete.

Rats in the LI group were watered with deionized water only and therefore received iodine only $1.2 \mu \mathrm{g} / \mathrm{d}$, from their feed. Rats of the other groups were given potassium iodate $\left(\mathrm{KIO}_{3}\right)$ dissolved in deionized water: the NI control group received $140 \mu \mathrm{g} / \mathrm{L}(5-6 \mu \mathrm{g} / \mathrm{d})$, and the $3 \mathrm{HI}$ group $480 \mu \mathrm{g} / \mathrm{L}(15-16 \mu \mathrm{g} / \mathrm{d})$. The rats were fed with the low iodine diet and administered with drinking water containing different concentrations of iodate from pre-pregnancy (12 weeks) until their pups reached PN21.

After 12 weeks of treatment, 6 female rats in each group were weighed and anesthetized with $10 \%$ chloral hydrate. Serum and thyroid samples were obtained and stored. Remaining rats $(\mathrm{n}=14$, each group) were mated with normal male Wistar rats (female:male $=2: 1$ ) and the next day a vaginal smear was obtained and analysed under a microscope to confirm the presence of spermatozoa. The rats with a smear positive for spermatozoa were considered mated and the day was recorded as G0. On G17, blood samples were collected from each pregnant rat of all groups for serum hormone analysis.

The pups from the rat mothers of each treatment group (LI, NI, and 3HI) were permitted free access to normal food and water from PN21 until PN45. On PN7 and PN45, the brains of six pups from each group (equal numbers of male and female pups from each group were chosen) were rapidly removed for immunohistochemistry and Western blot. Blood samples were drawn from the heart of the pups and serum were stored at $-70^{\circ} \mathrm{C}$.

On PN40-44, a Morris water maze was used for evaluating spatial learning and memory in the remaining offspring. 


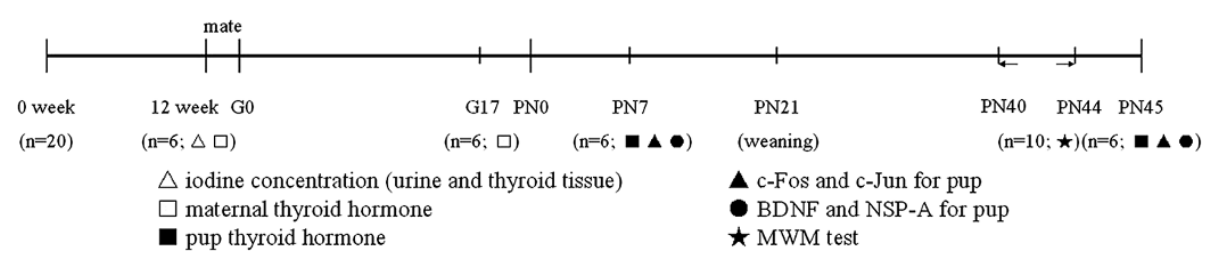

Figure 4 Schematic of experimental timeline. The rats were fed with the low iodine diet and administered with different drinking water from pre-pregnancy (12 weeks) until their pups reached PN21. LI $(1.2 \mu \mathrm{g} / \mathrm{d})$; NI $(5-6 \mu \mathrm{g} / \mathrm{d}) ; 3 \mathrm{HI}(15-16 \mu \mathrm{g} / \mathrm{d})$. The pups from the rat mothers of each treatment group (LI, NI, and 3HI) were permitted free access to normal food and water from PN21 until PN45. G, gestational day; PN, postnatal day; MWM, Morris water maze.

A schematic diagram of the experimental design and timeline is shown in Figure 4.

\section{Urinary and thyroidal iodine content measurement}

The rats were fed with the low iodine diet and administered with different drinking water for 12 weeks. Then 6 rats were randomly taken from different groups and urine samples were collected within 24 hours before euthanization. The rats were then deeply anesthetized and thyroid tissue samples were obtained. The iodine concentration was determined in urine and thyroid tissue homogenate by arsenic cerium catalytic spectrophotometry.

\section{Hormone measurements}

Blood samples were centrifuged at $3400 \times g$ for $15 \mathrm{~min}$. Serum $\mathrm{TT}_{4}, \mathrm{FT}_{4}$, and $\mathrm{TSH}$ concentrations were analysed via chemiluminescent immunoassay (IMMULITE, Diagnostic Products, CA). The limit of detection for $\mathrm{TT}_{4}$ was $1.0 \mu \mathrm{g} / \mathrm{dL}$, and any sample below this level was recorded as $1.0 \mu \mathrm{g} / \mathrm{dL}$ for statistical purposes. The upper limit of detection of $\mathrm{TT}_{4}$ was $24.0 \mu \mathrm{g} / \mathrm{dL}$. For $\mathrm{FT}_{4}$, the lower and upper limits of detection were $3.9 \mathrm{pmol} / \mathrm{L}$ and $77.2 \mathrm{pmol} /$ $\mathrm{L}$, respectively. For TSH, the lower and upper limits of detection were $0.002 \mathrm{mIU} / \mathrm{L}$ and $75 \mathrm{mIU} / \mathrm{L}$, respectively.

\section{Immunohistochemistry}

On PN7 and PN45, 6 pups were taken from different litters in each group, were deeply anesthetized and perfused with $200 \mathrm{~mL}$ saline followed by $200 \mathrm{~mL} 4 \%$ paraformaldehyde. Rat brains were embedded in paraffin and sectioned coronally with a microtome into $5 \mu \mathrm{m}$ sections. Sections were dewaxed and rehydrated and treated for endogenous peroxidase with 3\% methanolhydrogen peroxide for $10 \mathrm{~min}$.

All sections were incubated with the primary antibodies (c-Fos, 1:2000; c-Jun, 1:400; Abcam Biochemicals, England) at $4^{\circ} \mathrm{C}$ overnight and were then incubated with serum for $10 \mathrm{~min}$ at room temperature. The tissue sections were incubated in biotin-conjugated secondary antibodies (Maixin, Fuzhou, China) for $30 \mathrm{~min}$ at $37^{\circ} \mathrm{C}$, and in streptavidin-peroxidase complex (Maixin, Fuzhou, China) for $10 \mathrm{~min}$. Sections were treated with a solution of 3, 3'-diaminobenzidine (DAB; Maixin, Fuzhou, China) for 3 to 10 min depending upon the staining of the DAB reaction product observed under light microscopy. Finally, the sections were counterstained with hematoxylin, dehydrated, rinsed, and mounted in neutral gum (China National Medicines, Shanghai, China).

The hippocampal CA1 area of all sections was observed at $400 \times$. The integral optical density (IOD) values that indicated the expression levels of the proteins were measured using Image-Pro Plus 5.0 software (Media Cybernetics, Silver Spring, MD, USA).

\section{Western blot}

On PN7 and PN45, the brains of the 6 pups per treatment group were perfused with $200 \mathrm{~mL} 0.9 \%$ saline. Hippocampal samples were collected to assay BDNF and NSP-A protein expression by Western blot. Tissue samples were washed in lysis buffer containing protease and phosphatase inhibitors (Keygen Biotech, Nanjing, China), homogenized by sonication, and centrifuged at $10,000 \times g$ for $10 \mathrm{~min}$ at $4^{\circ} \mathrm{C}$. The supernatants were collected and the protein concentration was measured via the Coomassie brilliant blue assay. Tissue lysates were diluted and then boiled at $100^{\circ} \mathrm{C}$ for $5 \mathrm{~min}$. Samples $(50 \mu \mathrm{g})$ were fractionated via sodium dodecyl sulfate polyacrylamide gel electrophoresis $(10 \%$ gel for NSP-A, and $15 \%$ gel for BDNF). Proteins were transferred onto a nitrocellulose membrane and blocked with $5 \%$ skim milk in Tris-buffered saline containing $0.1 \%$ Tween-20 for one hour at room temperature. The membranes were washed and incubated with primary antibody (Rtn-1A [NSP-A] 1:500, Santa Cruz Biotechnology, USA; or BDNF 1:1000, Millipore, USA). An antibody against $\beta$-actin (1:1000; Santa Cruz Biotechnology, USA) was used as a reference. After incubation with primary antibodies, membranes were incubated with corresponding horseradish peroxidase-conjugated secondary antibodies (1:5000; Zhongshan Golden Bridge Biotechnology, China) before reaction with an enhanced chemiluminescence solution (Alphaview 1.3, USA). The films were scanned, and the protein band intensities were quantified with an image analysis program. 


\section{Morris water maze test}

The MWM was designed to assess spatial learning and memory in rodents [44]. The apparatus consists of a black circular swimming pool $(120 \mathrm{~cm}$ diameter, $50 \mathrm{~cm}$ depth) that was filled with water $\left(24 \pm 2^{\circ} \mathrm{C}\right)$ mixed with black edible pigment. The pool's four quadrants of equal area were designated $1,2,3$, and 4 . A circular platform (10 $\mathrm{cm}$ diameter) was located $2 \mathrm{~cm}$ below the water surface in the middle of quadrant 1 . The platform was the same colour as the black swimming pool water so that it the rats could not see it. The two investigators who administered the water maze test were always in the same position in the room.

The MWM test was performed on PN40-44. The entire test took 5 consecutive days with 8 training trials per day and 30-60 s inter-trial periods between two consecutive trials. The rat pups from the three groups $(\mathrm{n}=10$, each) were moved to the procedure room $30 \mathrm{~min}$ before testing. In each trial the rat was placed into the water, immediately facing the wall of the pool at an obvious compass location. The time required for the rat to find the platform (escape latency time) was recorded, with a maximal time of $120 \mathrm{~s}$ allowed. If the rat failed to locate the platform in the allowed time, a latency of $120 \mathrm{~s}$ was recorded. The rat was guided manually to the platform and allowed to stay on it for $10 \mathrm{~s}$ before being returned to its home cage.

\section{Statistical analysis}

All analyses were carried out using SPSS 17.0 software; the analyser was blind to the identity of the groups. All data results are presented as mean \pm SEM. Differences among the three groups were analysed using one-way analysis of variance (ANOVA). When the F-value indicated significance, post-hoc test (LSD) was used to correct for multiple comparisons. Differences were considered statistically significant at $P<0.05$.

\section{Abbreviations}

3HI: 3-fold iodine; AIN: American Institute of Nutrition; ANOVA: Analysis of variance; BDNF: Brain-derived neurotrophic factor; $\mathrm{FT}_{4}$ : Free thyroxine; $\mathrm{G}$ : Gestational; LI: Low iodine; $\mathrm{KIO}_{3}$ : Potassium iodate; MUI: Median urinary iodine; MWM: Morris water maze; NI: Normal iodine; NSP: Neuroendocrinespecific protein; PN: Postnatal; SPF: Specific pathogen-free; TSH: Thyrotropin or thyroid stimulating hormone; $\Pi_{4}$ : Total thyroxine; USI: Universal salt iodization.
\end{abstract}

\section{Competing interests}

The authors declare that they have no competing interests.

\section{Authors' contributions}

$\mathrm{LZ}, \mathrm{WT}$, and ZS conceived of the study and participated in its design and coordination. LZ drafted the manuscript. LZ, YL, JM, CF, HW and HZ carried out the experiments, collected and analyzed the data. WT and ZS revised the manuscript. All authors participated in writing the manuscript. All authors read and approved the final manuscript.

\section{Acknowledgments}

This work was supported by grants from the Education Department of Liaoning Province innovation team (LT2010108), Science and Technology Plan Foundation of Liaoning Province (2010225019), Doctoral Program of Higher education Fund (PhD programs fund) (20102104110005) and Association of Clinical Medical Research Special funds-Endocrine Diseases Research ([2010] 60) project Numbers (10020030225) funding. The authors are very grateful to the excellent theoretical and technical assistance from Prof. Zhongyan Shan and Prof. Weiping Teng from the Liaoning Provincial Key Laboratory of Endocrine Diseases.

Received: 21 May 2012 Accepted: 4 October 2012

Published: 8 October 2012

\section{References}

1. de Escobar GM, Obregón MJ, del Rey FE: Role of thyroid hormone during early brain development. Eur J Endocrinol 2004, 151(Suppl 3):U25-U37.

2. Zoeller RT, Rovet J: Timing of thyroid hormone action in the developing brain: Clinical observations and experimental findings. J Neuroendocrinol 2004, 16(10):809-818.

3. Chen ZP, Hetzel BS: Cretinism revisited. Best Pract Res Clin Endocrinol Metab 2010, 24(1):39-50.

4. Skeaff SA: lodine deficiency in pregnancy: the effect on neurodevelopment in the child. Nutrients 2011, 3(2):265-273.

5. Zimmermann MB: The role of iodine in human growth and development. Semin Cell Dev Biol 2011, 22(6):645-652.

6. Teng W, Shan Z, Teng X, Guan H, Li Y, Teng D, Jin Y, Yu X, Fan C, Chong W, Yang F, Dai H, Yu Y, Li J, Chen Y, Zhao D, Shi X, Hu F, Mao J, Gu X, Yang R, Tong Y, Wang W, Gao T, Li C: Effects of iodine intake on thyroid diseases in China. N Engl J Med 2006, 354(26):2783-2793.

7. Dong J, Yin H, Liu W, Wang P, Jiang Y, Chen J: Congenital iodine deficiency and hypothyroidism impair LTP and decrease c-Fos and c-Jun expression in rat hippocampus. Neurotoxicology 2005, 26(3):417-426.

8. Guzowski JF: Insights into immediate-early gene function in hippocampal memory consolidation using antisense oligonucleotide and fluorescent imaging approaches. Hippocampus 2002, 12(1):86-104.

9. Opazo MC, Gianini A, Pancetti F, Azkcona G, Alarcón L, Lizana R, Noches V Gonzalez PA, Marassi MP, Mora S, Rosenthal D, Eugenin E, Naranjo D, Bueno SM, Kalergis AM, Riedel CA: Maternal hypothyroxinemia impairs spatial learning and synaptic nature and function in the offspring. Endocrinology 2008, 149(10):5097-5106.

10. Liu D, Teng W, Shan Z, Yu X, Gao Y, Wang S, Fan C, Wang H, Zhang H: The effect of maternal subclinical hypothyroidism during pregnancy on brain development in rat offspring. Thyroid 2010, 20(8):909-915.

11. Lasley SM, Gilbert ME: Developmental thyroid hormone insufficiency reduces expression of brain-derived neurotrophic factor (BDNF) in adults but not in neonates. Neurotoxicol Teratol 2011, 33(4):464-472.

12. Dowling ALS, lannacone EA, Zoeller RT: Maternal hypothyroidism selectively affects the expression of neuroendocrine-specific protein a messenger ribonucleic acid in the proliferative zone of the fetal rat brain cortex. Endocrinology 2001, 142(1):390-399.

13. Dong J, Liu W, Wang Y, Hou Y, Xi Q, Chen J: Developmental iodine deficiency resulting in hypothyroidism reduces hippocampal ERK1/2 and CREB in lactational and adolescent rats. BMC Neurosci 2009, 10:149.

14. Gong J, Liu W, Dong J, Wang Y, Xu H, Wei W, Zhong J, Xi Q, Chen J: Developmental iodine deficiency and hypothyroidism impair neural development in rat hippocampus: involvement of doublecortin and NCAM-180. BMC Neurosci 2010, 11:50

15. Anderson GW, Schoonover CM, Jones SA: Control of Thyroid Hormone Action in the Developing Rat Brain. Thyroid 2003, 13(11):1039-1056.

16. Babikian T, Prins ML, Cai Y, Barkhoudarian G, Hartonian I, Hovda DA, Giza CC: Molecular and physiological responses to juvenile traumatic brain injury: focus on growth and metabolism. Dev Neurosci 2010, 32(5-6):431-441.

17. Evans IM, Pickard MR, Sinha AK, Leonard AJ, Sampson DC, Ekins RP: Influence of maternal hyperthyroidism in the rat on the expression of neuronal and astrocytic cytoskeletal proteins in fetal brain. $J$ Endocrinol 2002, 175(3):597-604.

18. Gilbert ME, Sui L, Walker MJ, Anderson W, Thomas S, Smoller SN, Schon JP, Phani S, Goodman JH: Thyroid hormone insufficiency during brain development reduces parvalbumin immunoreactivity and inhibitory function in the hippocampus. Endocrinology 2007, 148(1):92-102. 
19. Hwang S, Lee EY, Lee WK, Shin DY, Lee EJ: Correlation between iodine intake and thyroid function in subjects with normal thyroid function. Biol Trace Elem Res 2011, 143(3):1393-1397.

20. Orito $Y$, Oku H, Kubota S, Amino N, Shimogaki K, Hata M, Manki K, Tanaka Y, Sugino S, Ueta M, Kawakita K, Nunotani T, Tatsumi N, Ichihara K, Miyauchi A, Miyake M: Thyroid Function in Early Pregnancy in Japanese Healthy Women: Relation to Urinary lodine Excretion, Emesis, and Fetal and Child Development. J Clin Endocrinol Metab 2009, 94(5):1683-1688.

21. Thomopoulos P: lodine excess and thyroid dysfunction. La Revue du Praticien 2005, 55(2):180-182.

22. Bourdoux PP, Ermans AM, Mukalay wa Mukalay A, Filetti S, Vigneri R: lodine induced thyrotoxicosis in Kiwu Zaire. Lancet 1996, 347(9000):552-553.

23. Fradkin JE, Wolff J: lodide-induced thyrotoxicosis. Medicine (Baltimore) 1983, 62(1):1-20.

24. Connolly RJ, Vidor Gl, Stewart JC: Increase in thyrotoxicosis in endemic goitre area after iodation of bread. Lancet 1970, 1(7645):500-502.

25. Leung AM, Braverman LE: lodine-induced thyroid dysfunction. Curr Opin Endocrinol Diabetes Obes 2012, 19(5):414-419.

26. Sebotsa ML, Dannhauser $\mathrm{A}$, Jooste $\mathrm{PL}$, Joubert $\mathrm{G}$ : lodine status as determined by urinary iodine excretion in Lesotho two years after introducing legislation on universal salt iodization. Nutrition 2005, 21(1):20-24

27. Lewiński A, Szybiński Z, Bandurska-Stankiewicz E, Grzywa M, Karwowska A, Kinalska I, Kowalska A, Makarewicz J, Nauman J, Słowińska-Klencka D, Sowiński J, Syrenicz A, Zonenberg A, Huszno B, Klencki M: lodine-induced hyperthyroidism-an epidemiological survey several years after institution of iodine prophylaxis in Poland. J Endocrinol Invest 2003, 26(2 Suppl):57-62.

28. Morreale de Escobar G, Pastor R, Obregon MJ, Escobar del Rey F: Effects of maternal hypothyroidism on the weight and thyroid hormone content of rat embryonic tissues, before and after onset of fetal thyroid function. Endocrinology 1985, 117(5):1890-1900.

29. Ahmed OM, El-Gareib AW, El-Bakry AM, Abd El-Tawab SM, Ahmed RG: Thyroid hormones states and brain development interactions. Int I Dev Neurosci 2008, 26(2):147-209.

30. Chen C, Zhou Z, Zhong M, Li M, Yang X, Zhang Y, Wang Y, Wei A, Qu M, Zhang L, Xu S, Chen S, Yu Z: Excess thyroid hormone inhibits embryonic neural stem/progenitor cells proliferation andmaintenance through STAT3 signalling pathway. Neurotox Res 2011, 20(1):15-25.

31. Ahmed OM, Abd El-Tawab SM, Ahmed RG: Effects of experimentally induced maternal hypothyroidism and hyperthyroidism on the development of rat offspring: I. The development of the thyroid hormones-neurotransmitters and adenosinergic system interactions. Int J Dev Neurosci 2010, 28(6):437-454.

32. Emder PJ, Jack MM: lodine-induced neonatal hypothyroidism secondary to maternal seaweed consumption: A common practice in some Asian cultures to promote breast milk supply. J Paediatr Child Health 2011, 47(10):750-752.

33. Gao TS, Teng WP, Shan ZY, Jin $Y$, Guan HX, Teng XC, Yang F, Wang WB, Shi $X G$, Tong YJ, Li D, Chen W: Effect of different iodine intake on schoolchildren thyroid diseases and intelligence in rural areas. Chin Med $J$ (Engl) 2004, 117(10):1518-1522.

34. Chung HR, Shin CH, Yang SW, Choi CW, Kim Bl: Subclinical hypothyroidism in Korean preterm infants associated with high levels of iodine in breast milk. J Clin Endocrinol Metab 2009, 94(11):4444-4447.

35. Herdegen T, Skene P, Bähr M: The c-Jun transcription factor-bipotential mediator of neuronal death, survival and regeneration. Trends Neurosci 1997, 20(5):227-231.

36. Wang $Y$, Su B, Xia Z: Brain-derived neurotrophic factor activates ERK5 in cortical neurons via a Rap1-MEKK2 signaling cascade. J Biol Chem 2006, 281(47):35965-35974.

37. Lewin GR, Barde YA: Physiology of the neurotrophins. Annu Rev Neurosci 1996, 19:289-317.

38. Lu B, Figurov A: Role of neurotrophins in synapse development and plasticity. Rev Neurosci 1997, 8(1):1-12.

39. Heldt SA, Stanek L, Chhatwal JP, Ressler KJ: Hippocampus-specific deletion of BDNF in adult mice impairs spatial memory and extinction of aversive memories. Mol Psychiatry 2007, 12(7):656-670.

40. Chakraborty G, Magagna-Poveda A, Parratt C, Umans JG, MacLusky NJ, Scharfman HE: Reduced hippocampal brain-derived neurotrophic factor
(BDNF) in neonatal rats after prenatal exposure to propylthiouracil (PTU). Endocrinology 2012, 153(3):1311-1316.

41. Wang S, Teng W, Gao Y, Fan C, Zhang H, Shan Z: Early levothyroxine treatment on maternal subclinical hypothyroidism improves spatial learning of offspring in rats. J Neuroendocrinol 2012, 24(5):841-848.

42. Senden NH, Timmer ED, Boers JE, van de Velde $\mathrm{HJ}$, Roebroek AJ, Van de Ven WJ, Broers JL, Ramaekers FC: Neuroendocrine-specific protein C (NSP-C): subcellular localization and differential expression in relation to NSP-A. Eur J Cell Biol 1996, 69(3):197-213.

43. Dowling ALS, Martz GU, Leonard JL, Zoeller RT: Acute changes in maternal thyroid hormone induce rapid and transient changes in gene expression in fetal rat brain. J Neurosci 2000, 20(6):2255-2265.

44. Brown RW, Flanigan TJ, Thompson KN, Thacker SK, Schaefer TL, Williams MT: Neonatal quinpirole treatment impairs Morris water task performance in early postweanling rats: relationship to increases in corticosterone and decreases in neurotrophic factors. Biol Psychiatry 2004, 56(3):161-168.

doi:10.1186/1471-2202-13-121

Cite this article as: Zhang et al:: Effect of maternal excessive iodine intake on neurodevelopment and cognitive function in rat offspring. BMC Neuroscience 2012 13:121.

\section{Submit your next manuscript to BioMed Central and take full advantage of:}

- Convenient online submission

- Thorough peer review

- No space constraints or color figure charges

- Immediate publication on acceptance

- Inclusion in PubMed, CAS, Scopus and Google Scholar

- Research which is freely available for redistribution 